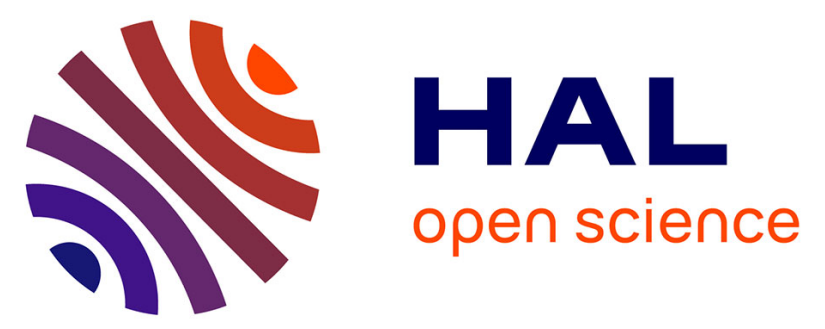

\title{
Centrifuge investigation of the axial cyclic behaviour of a single pile used for the foundation of a jacket type offshore wind turbine
}

Mathieu Blanc, Luc Thorel, Rocio Isorna, Christophe Dano, Panagiotis Kotronis, Maxime Philippe

\section{To cite this version:}

Mathieu Blanc, Luc Thorel, Rocio Isorna, Christophe Dano, Panagiotis Kotronis, et al.. Centrifuge investigation of the axial cyclic behaviour of a single pile used for the foundation of a jacket type offshore wind turbine. 3rd International Symposium on Frontiers in Offshore Geotechnics (ISFOG2015), Jun 2015, Oslo, Norway. pp.521-526, 10.1201/b18442-65 . hal-01503353

\section{HAL Id: hal-01503353 \\ https://hal.science/hal-01503353}

Submitted on 7 Apr 2017

HAL is a multi-disciplinary open access archive for the deposit and dissemination of scientific research documents, whether they are published or not. The documents may come from teaching and research institutions in France or abroad, or from public or private research centers.
L'archive ouverte pluridisciplinaire HAL, est destinée au dépôt et à la diffusion de documents scientifiques de niveau recherche, publiés ou non, émanant des établissements d'enseignement et de recherche français ou étrangers, des laboratoires publics ou privés.

\section{(c) (1) $\$$}

Distributed under a Creative Commons Attribution - NonCommerciall 4.0 International 


\title{
Centrifuge investigation of the axial cyclic behaviour of a single pile used for the foundation of a jacket type offshore wind turbine
}

\author{
M. Blanc \& L. Thorel \\ Earthworks and Centrifuge Laboratory, GERS Department, IFSTTAR, LUNAM University, Bouguenais, France
}

R. Isorna, C. Dano \& P. Kotronis

GeM, CNRS, Ecole Central de Nantes, LUNAM University, Nantes, France

M. Philippe

INNOSEA, Nantes, France

\begin{abstract}
The jacket type offshore wind turbine transfers efficiently the horizontal load applied on the wind turbine to an axial load on the four piles of its foundation. The axial behaviour of one single pile of the foundation is investigated in a geotechnical centrifuge. The model pile, tested under a $100 \mathrm{~g}$ centrifuge acceleration, is designed to represent a cast-in-place pile with a $1.8 \mathrm{~m}$ diameter and a $40 \mathrm{~m}$ embedded length. The pile, installed in dense Fontainebleau sand, is instrumented with a load sensor at its end to measure the tip resistance. By subtracting the total load applied on the pile, its shaft capacity is also calculated. Different axial loading paths are applied: i) monotonic loadings in compression and tension to obtain ultimate capacities and ii) cyclic loadings which represent a more realistic loading path applied by the jacket during its life time in order to observe the tip and shaft capacities reductions.
\end{abstract}

\section{INTRODUCTION}

Offshore wind turbines are subjected to complex loading due to environmental conditions. In case of a jacket foundation, lateral loads are transferred to axial loads on the four vertical piles. Pile foundations under axial load need special attention for their design. A possible way to follow consists in using CPT methods (for example ICP-05, UWA-05, Fugro-05 or NGI-05, which are summarized in Scheneider et al. (2008)).

Another key issue of the design of the pile foundation is the effect of cyclic loading. Historically, it has been taken into account by the off-shore petroleum industry through international standards as API (2011) and DNV (1977). In Europe, there is also some recommendation, which comes from the on-shore standard: Eurocode 7 (2005). It only mentions that cyclic loads must be identified in order to be considered in a specific way with regard to continuation of motion, soil liquefaction and change of stiffness and resistance of soil.

In order to fill the gap of knowledge about the impact of cyclic loading on pile foundation, the French National Program SOLCYP has been launched in 2008. It has, first, only dealt with on-shore foundation (much smaller than off-shore). In this program experiments have been carried out in the IFSTTAR centrifuge on lateral loading of pile in sand (Rosquoët et al. 2013) or in clay (Khemakhem et al. 2012) and on axial loading in sand (Guefrech et al. 2012). Using these centrifuge results among other tests, Anderson et al. (2013) describe a procedure to design off-shore foundations for wind turbines. However, nearly all the experimental results used come from experiments designed for on-shore issues, on-shore deep foundations are smaller size than off-shore foundations.

For this reason, in this study, the large piles problematic ( $40 \mathrm{~m}$ long and $1.8 \mathrm{~m}$ diameter) is studied through centrifuge tests performed at $100 \mathrm{xg}$. The focus is on the axial behaviour of a single pile where the load analysis includes the decomposition into the shaft and the tip capacities and also the effects of cyclic loading.

\section{EXPERIMENTAL METHODOLOGY}

\subsection{Model pile}

Large single piles embedded in sand were tested under a $100 \mathrm{~g}$ centrifuge acceleration in the IFSTTAR beam centrifuge. For this experimental campaign, the centrifuge acceleration was applied at a radius of $4.94 \mathrm{~m}$. The prototype pile studied was a cast-in-place pile with a $1.8 \mathrm{~m}$ diameter and a $40 \mathrm{~m}$ embedded length. The model pile used (Figure 1) was an aluminum cylinder with an outside diameter of $1.8 \mathrm{~cm}$ and a total length to of $45 \mathrm{~cm}$ (only $40 \mathrm{~cm}$ are embedded in the soil sample) to respect the scaling law on the length. The pile tip 


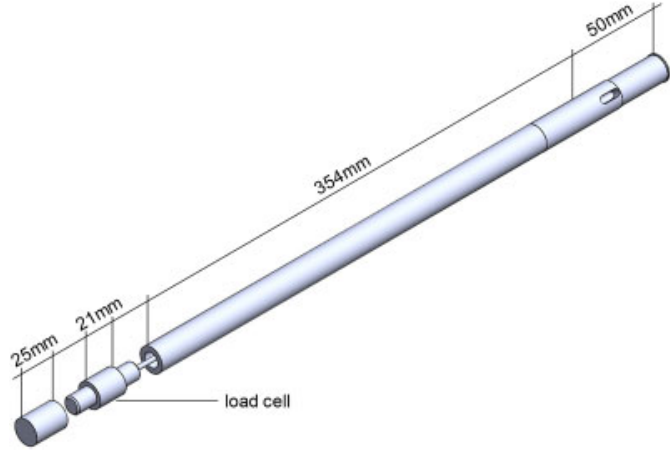

Figure 1. Model pile.

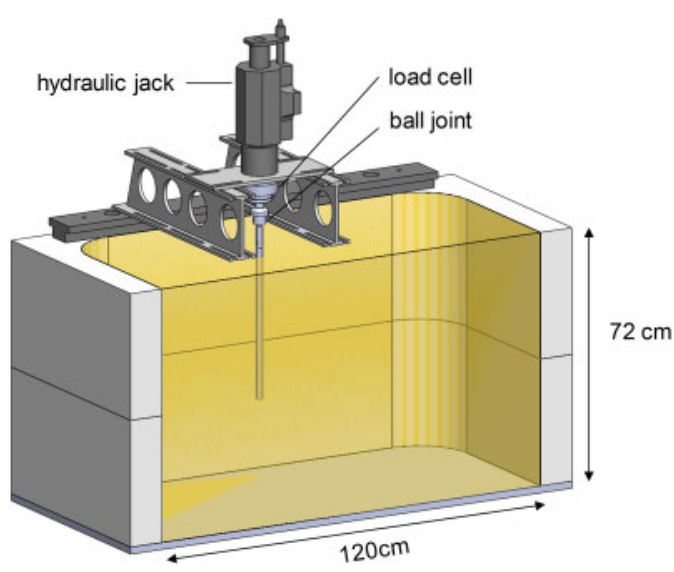

Figure 2. Experimental set up installed in the swinging basket of the centrifuge.

was flat and close-ended. The pile surface was rough, and the roughness is obtained by mechanical machining in order to obtain a normalized roughness (Lings and Dietz, 2005) equal to 1.

The connection with a ball joint between the vertical hydraulic jack and the pile head induces a zero moment (Figure 2). A load cell is also positioned between them in order to measure the overall bearing capacity. The pile toe is also instrumented with a load cell located $4.6 \mathrm{~cm}$ above the toe. This combination of the two load cells in the head and the toe of the pile allows, after some correction explained later, to decompose the bearing capacity into shaft and tip resistance.

\subsection{Soil sample}

The model soil was the Fontainebleau sand NE34, which has a minimum density of $1.417 \mathrm{~g} / \mathrm{cm}^{3}$ and a maximum density of $1.736 \mathrm{~g} / \mathrm{cm}^{3}$. The medium particle diameter is around $0.2 \mathrm{~mm}$ and the sand has a coefficient of uniformity $C_{u}=1.6$.

The dry sand was filled using the air pluviation technique in a rigid rectangular container with inner dimensions of $120 \mathrm{~cm}$ in length, $80 \mathrm{~cm}$ in width and $72 \mathrm{~cm}$ in depth. The relative sand density is controlled
Table 1. Monotonic loading tests (prototype scale).

\begin{tabular}{llll}
\hline Test & $\begin{array}{l}\text { Load } \\
\text { case }\end{array}$ & $\begin{array}{l}\text { Capacity } \\
{[\mathrm{MN}]}\end{array}$ & $\begin{array}{l}\text { Internal friction } \\
\text { angle from ICP } \\
{\left[{ }^{\circ}\right]}\end{array}$ \\
\hline T1 & comp. & 107 & 29 \\
T2 & comp. & 98 & 25 \\
T3 & tension & -43 & 20 \\
\hline
\end{tabular}

by adjusting the falling height, the flow rate and the speed of the automatic hopper. For this experimental campaign, these parameters have been adjusted to obtain a density index of $92 \%$ (controlled after tests by using two calibrated boxes previously placed at the bottom of the container).

Once the model soil prepared, 8 piles were driven at $1 \mathrm{~g}$ (before the $\mathrm{g}$ level increases), with a minimum distance from the walls equal to 10 times the pile diameter. The distance between the pile tip and the bottom of the container is also above 10 pile diameters.

\subsection{Test chronology}

After the preparation of the soil model and the driving of the model pile at $1 \mathrm{~g}$, the centrifuge acceleration was increased to $100 \mathrm{~g}$. After the g increase, the loading path of the pile is applied by the hydraulic jack with two possibilities of monitoring following the purpose of the test. First, for axial capacity tests, the jack is controlled by displacement and the loads are measured. Second possibility, for cyclic tests, the head load is controlled and the displacement of the jack is monitored.

\subsection{Experimental campaign}

First of all, the static axial capacity of the pile should be studied. Once the ultimate axial capacity in compression $Q_{r c}$ and in tension $Q_{r t}$ are obtained, the cyclic loading program can be determined. It has been decided to study the cyclic behaviour of the pile through 2 series of 3 cyclic tests: one series purely in tension (one way test) and the second alternating between compression and tension phases (two-way test).

\section{MONOTONIC LOADING}

\subsection{Axial capacity}

3 monotonic loading tests are first carried out, 2 in compression and 1 in tension (Table 1), in order to estimate the ultimate axial capacity of the pile. The experimental results (Figure 3(a)) show the loads of the head and tip sensors versus the pile head displacement normalized by the pile diameter. 
The value of the head load sensor provides directly the axial capacity. The tension resistance $Q_{r t}$ is determined when the measured load reaches a minimum peak value and the compression resistance $Q_{r c}$ is estimated at the slope breaking point of load-displacement curve. The results are reported in the Table 1. The two $Q_{r c}$ values are rather close but the tension resistance is less than $50 \%$ of the one in compression. Generally, for cast in place piles, the difference between $Q_{r t}$ and $Q_{r c}$ is less important. However, this experiment doesn't model a cast in place pile because the pile has been driven at $1 \mathrm{~g}$. Then, during the driving, the characteristics of the soil sample have certainly been modified around the pile. To conclude, the model pile is between a cast in place and driven pile. The ratio between $Q_{r t}$ and $Q_{r c}$ is 0.65 for driven piles (Guefrech et al. 2012) and under 0.2 for a driven pile (Nivoche 2014).

During these monotonic tests, the value of the load sensor near the toe of the pile ( $4.6 \mathrm{~m}$ above) has also been recorded. Contrary to the head load, near the toe, the load doesn't start from zero but from around $20 \mathrm{MN}$. It is possible because, during the $\mathrm{g}$ increase, some positive and negative friction develops around the pile. During the g increase, the soil sample settles more in surface than at depth whereas the pile, assumed to be rigid, settles uniformly. Then, above a depth, the soil pushes the pile down whereas under this depth, the pile is hold by the soil. For this reason, the initial load near the toe starts for a positive value. During the test, this value doesn't represent the tip resistance because the sensor is not exactly at the toe but $4.6 \mathrm{~m}$ above. The lateral friction around this end of the pile should be removed to obtain the overall tip and shaft capacities.

\subsection{Interface angle of friction}

The shaft capacity $Q_{s}$ is the integral of the local shear stresses $\tau_{f}$ along the embedded shaft length:

$Q_{s}=\pi D \int \tau_{f} d z$

Using the Coulomb failure criterion, the local shear stress $\tau_{f}$ can be calculated from the local radial effective stress $\sigma_{r f}^{\prime}$ :

$$
\tau_{f}=\sigma_{r f}^{\prime} \tan \delta
$$

with $\delta$ the interface friction angle.

To calculate the local radial effective stress $\sigma_{r f}^{\prime}$, the ICP method is used (Jardine et al., 2005). $\sigma_{r f}{ }_{r f}$ is the sum of the equalized value acting few days after installation $\sigma_{r c}^{\prime}$ and the dilatant increase during pile loading $\Delta \sigma^{\prime}{ }_{r d}$ :

$$
\sigma_{r f}^{\prime}=\left\{\begin{array}{l}
\sigma_{r c}^{\prime}+\Delta \sigma_{r d}^{\prime} \text { in comp. } \\
0.8 \sigma_{r c}^{\prime}+\Delta \sigma_{r d}^{\prime} \text { in tension }
\end{array}\right.
$$
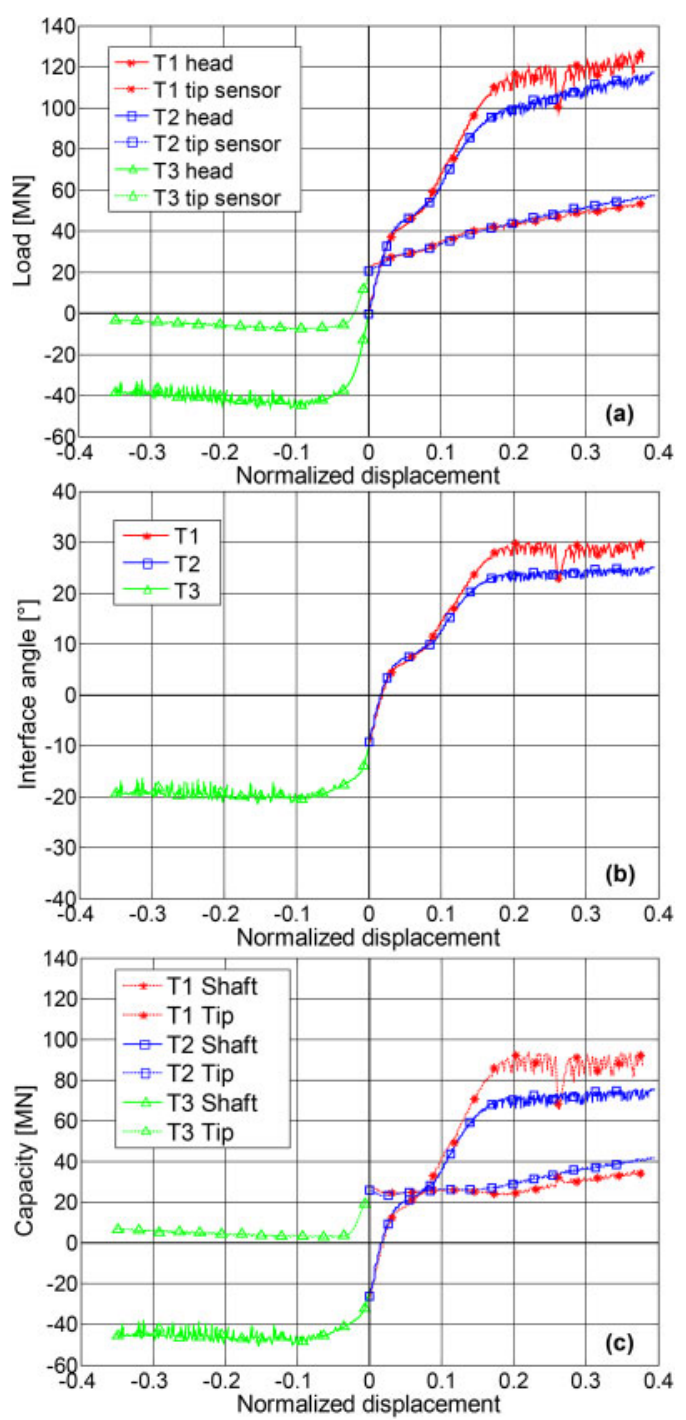

Figure 3. Monotonic loading tests (prototype scale) - (a) load sensors, (b) internal friction angle \& (c) shaft and tip resistances versus the normalized displacement.

The equalized value $\sigma_{r c}^{\prime}$ is a function of the CPT resistance $q_{c}$, the free field vertical stress and the $h / R$ ratio (where $h$ is the distance from the tip):

$\sigma_{r c}^{\prime}=\frac{q_{c}}{34}\left(\frac{h}{R}\right)^{-0.38}\left(\frac{\sigma_{v 0}^{\prime}}{P_{a}}\right)^{0.13}$

The dilatant increase $\Delta \sigma_{r d}^{\prime}$, less important, is related to the sand shear stiffness, the pile roughness and the radius:

$\Delta \sigma_{r d}^{\prime}=2 G_{s} \frac{\Delta r}{R}$

where $G_{s}$ can be obtained from the CPT resistance. 


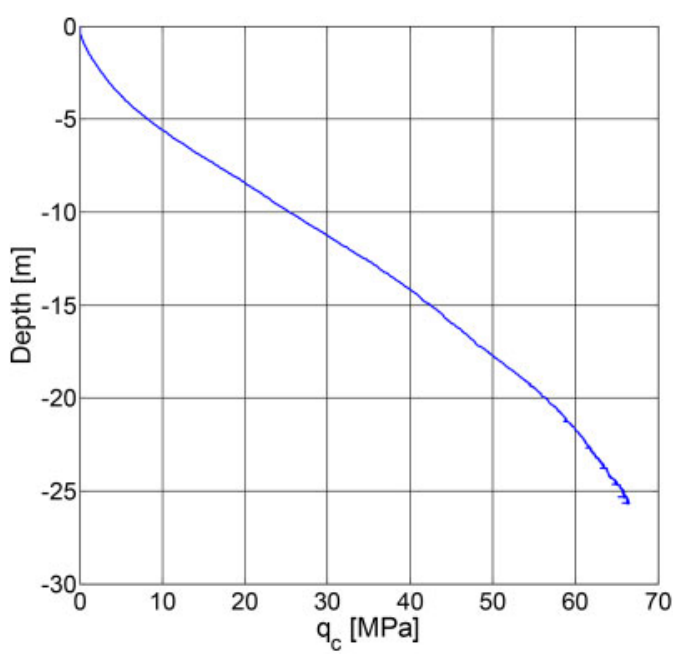

Figure 4. CPT test performed during this campaign.

The only unknown of the ICP method is the CPT resistance $q_{c}$. For the Fontainebleau sand at the relative density of this experimental campaign, $q_{c}$ has been measured and compared by Bolton et al. (1999) from CPT performed in different centrifuge labs: $q_{c}=2.7 z$ in MPa (with $z$ in $\mathrm{m}$ ). A CPT has also been performed during this campaign. This test, exposed in the Figure 4, gives the same tendency.

The difference between the head load and the one given by the sensor near the toe gives the shaft capacity of the upper part of the embedded pile. Then the interface friction angle $\delta$ can be calculated (Figure 3(a)). For the tests in compression, the value at failure is $29^{\circ}$ and $25^{\circ}$ and, the test in tension, it is $20^{\circ}$. The values in compression are in good agreement the practice whereas the one in tension is too low.

By using these values of the interface friction angle on the entire embedded pile, it is possible to decompose the head load into the tip and the shaft capacities.

\subsection{Decomposition in tip and shaft capacities}

On Figure 3(c), are represented the tip and the shaft resistances during the monotonic loading tests. Due to some positive and negative settlements during the acceleration increase, the initial values of the tip and the shaft resistances are not negligible (the tip is positive whereas the shaft is negative).

From this initial state, for tests in compression, two behaviours may occur: i) before the failure (for normalized displacement under $17 \%$ ), the shaft resistance increases whereas the tip remains constant; ii) after the failure, the shaft stays constant around $80 \mathrm{MN}$ but now the tip increases. It means that all the friction between the pile and the soil has been mobilized and the increase of the bearing capacity is only due to the tip where some compaction of the soil sample may occur.
For the test in tension, the behaviour is totally different. First, until 3\% of normalized displacement, the tip resistance deceases rapidly until a minimum value slightly positive: there is no more tip resistance. And there is only positive friction. Then the failure happens for $10 \%$ of normalized displacement which is sooner than for the compression tests. The shaft capacity is then $-47 \mathrm{MN}$ which is less than the one in compression. The shaft capacity is not the same in tension than in compression. One possible explanation may come from the driving of the pile at $1 \mathrm{~g}$.

\section{CYCLIC LOADING}

\subsection{Effect of axial cycling}

For the cyclic tests, the load control mode is used to perform the cyclic sequences. Four parameters are needed to describe the cyclic sequence: i) the mean load $Q_{m}$ ii) the half load amplitude $Q_{c}$ iii) the period of the cycle and iv) the number of cycles. First, the load is increased up to $Q_{m}$. Then the sine signal is applied at a frequency of $0.1 \mathrm{~Hz}$. The cyclic load components can be expressed as a rate of the ultimate bearing capacity deduced from the monotonic loading tests.

In pile behaviour studies, cyclic loading is classically split in two categories: one-way or two-way tests. The latter is obtained when the cyclic magnitude $Q_{c}$ is greater than the mean load value $Q_{m}$ whatever the sign of $Q_{m}$. As mentioned earlier, 2 series of 3 cyclic tests have been performed: one purely in tension (one way) and the second alternating between compression and tension phases (two ways). The characteristics of these tests are given by the Table 2 .

Figure 5 presents the typical results of a cyclic test. The cyclic test presented is the one way in pure tension T4. The load cycles between 0 and $-36 \mathrm{MN}$. On the Figure 5(a) is presented the load versus normalized displacement curve. With the number of cycles, the normalized displacement increases. Suddenly, around $35 \%$ of the normalized displacement, in few cycles, the pile goes out whereas the load stays above the axial capacity in tension $\left(Q_{r t}=-43 \mathrm{MN}\right)$. It corresponds to the cyclic failure of the pile which can be characterized by two parameters: i) the number of cycles to get to the failure and ii) the normalized displacement when it happens. To obtain these parameters, the normalized displacement has been plotted versus the number of cycles (Figure 5(b)). First, the medium displacement rate is constant, then, it suddenly increases. This slope breaking point defines the failure. For this test, it happens after 230 cycles for a normalized displacement around $35 \%$.

\subsection{Stability diagram}

To evaluate the response of piles to cyclic loading Poulos (1988) proposed a cyclic stability diagram in which the mean and cyclic axial loads are plotted. Three regions can be identified: i) a cyclically stable 
Table 2. Cyclic loading tests (prototype scale).

\begin{tabular}{|c|c|c|c|c|c|}
\hline Test & way(s) & $\begin{array}{l}Q_{m} \\
{[\mathrm{MN}]}\end{array}$ & $\begin{array}{l}Q_{c} \\
{[\mathrm{MN}]}\end{array}$ & $Q_{c} / Q_{m}$ & $\begin{array}{l}\text { nbr of cycles } \\
\text { at failure }\end{array}$ \\
\hline $\mathrm{T} 4$ & 1 & -18.0 & 18.0 & -1.0 & 230 \\
\hline T5 & 1 & -12.0 & 12.0 & -1.0 & $>1500$ \\
\hline T6 & 1 & -20.0 & 20.0 & -1.0 & 133 \\
\hline $\mathrm{T} 7$ & 2 & 2.2 & 4.2 & 1.8 & $>1500$ \\
\hline $\mathrm{T} 8$ & 2 & 11.4 & 21.0 & 1.8 & $>1500$ \\
\hline T9 & 2 & 18.4 & 33.7 & 1.8 & 33 \\
\hline
\end{tabular}
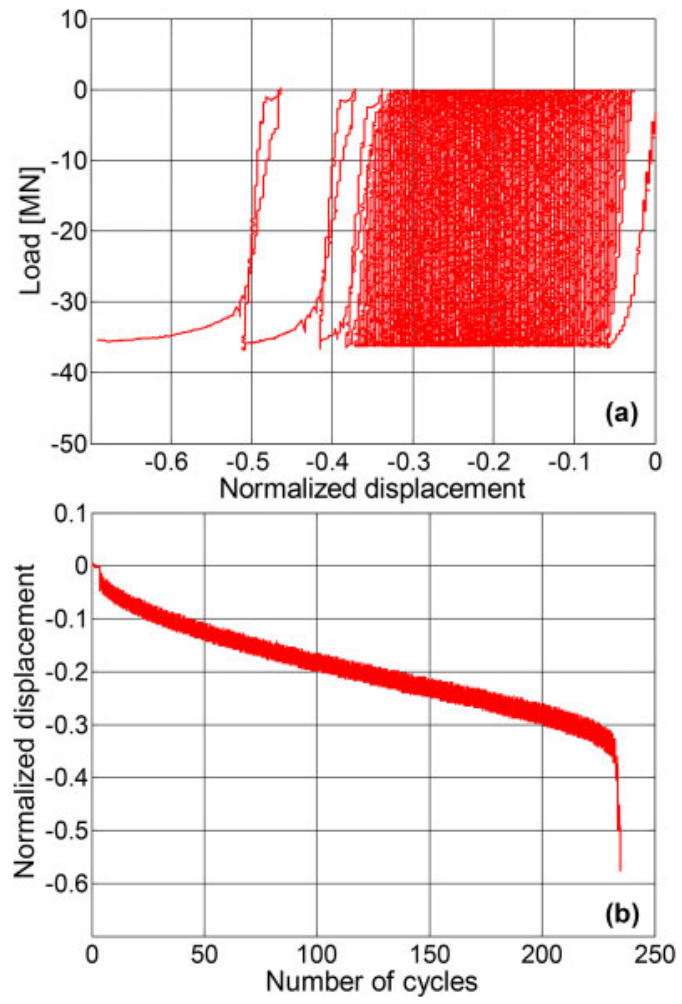

Figure 5. Cyclic test T4 in pure tension (prototype scale) (a) head load versus normalized displacement (b) normalized displacement versus number of cycles.

region where the cyclic loading has no effect on the pile capacity (more than 1500 cycles without faillure); ii) a cyclically metastable region where the cyclic loading causes limited reduction of the load capacity; and iii) a cyclically unstable region where the cyclic loading results in failure of the pile within a specified number of cycles (less than 100 cycles).

On the Figure 6, is presented the cyclic stability diagram for this model pile in which the loads have been normalized by the axial ultimate resistance in compression $Q_{r c}$. On the $\mathrm{X}$ axis there is the ratio between $Q_{m}$ applied and $Q_{r c}$. On the $\mathrm{Y}$ axis there is the ratio between $Q_{c}$ applied and $Q_{r c}$. The domain of possible loads is limited by an envelope that has a triangular

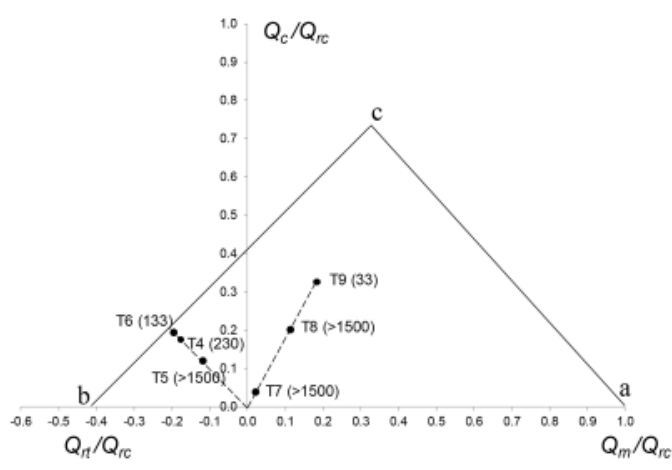

Figure 6. Stability diagram of the cyclic tests.

shape a-b-c; a is the point when $Q_{m}$ is equal to $Q_{r c}$ so $Q_{r c} / Q_{r c}=1 ; \mathrm{b}$ is the point when $Q_{m}$ is equal to $Q_{r t}$ so $Q_{r t} / Q_{r c}=-0.42$ and c value is on the $\mathrm{X}$ axis 0.29 and on the $\mathrm{Y}$ axis 0.71 . The lines $\mathrm{a}-\mathrm{c}$ and $\mathrm{c}-\mathrm{b}$ represents the monotonic tests. From these two points, the right side cross the $\mathrm{Y}$ axis at $Q_{c} / Q_{r c}=Q_{r c} / Q_{r c}=1$ whereas the left side at $Q_{c} / Q_{r c}=Q_{r t} / Q_{r c}=-0.42$.

The two series of tests are represented in this diagram on two lines starting from the origin with a slope of $Q_{c} / Q_{m}=-1.0$ (one way in pure tension) and 1.8 (two ways). For each test, the number of cycles at failure is noted. For some of them, in the stable region, the failure has not been reached after 1500 cycles: it is noted " $>1500$ ". For the other tests, in the metastable region, closer to the lateral sides of the envelop triangle the load is, sooner the failure occurs.

\section{CONCLUSION}

The axial behaviour of a single pile (with a $1.8 \mathrm{~m}$ diameter and a $40 \mathrm{~m}$ embedded length) used in the foundation of a jacket type offshore wind turbine is studied in centrifuge at $100 \mathrm{~g}$. The model pile is driven at $1 \mathrm{~g}$ in soil model made of Fontainebleau sand NE34 filled by air pluviation.

The axial capacity of the pile is determined from monotonic tests in tension and in compression. The tension resistance $Q_{r t}$ value is $-43 \mathrm{MN}$ and the compression one $Q_{r c}$ is $102 \mathrm{MN}$.

By using the ICP method, the interface friction angle is calculated from the difference between the load sensors (in the head and near the tip). Then the axial capacity can be decomposed into the shaft and the tip resistances. Due to settlements during the increase in acceleration, some negative and positive frictions are developing along the pile, which involves some shaft and tip resistance before applying the loading.

For compression tests, first, the shaft resistance increases whereas the tip remains constant. Then, as soon as all the friction around the pile is mobilized, only the tip increases, certainly due to compaction under the tip. For tension tests, first, the tip resistance 
deceases rapidly until a minimum value slightly positive. Then, the axial capacity depends only on the shaft resistance.

Cyclic tests have been plotted in the Poulos (1988) stability diagram. By analyzing the failures, the shapes of the stability regions (stable, metastable and unstable) have been revealed.

\section{ACKNOWLEDGMENTS}

The authors thank the Region Pays de la Loire for providing financial support for this work through the CHARGEOL project.

\section{REFERENCES}

Andersen, K., Puech, A. \& Jardine, R. 2013. Cyclic resistant geotechnical design and parameter selection for offshore engineering and other applications. Design for cyclic loading : Piles and other foundations, Proceeding of TC 209 Workshop - 18th ICSMGE, Paris : 9-44.

API RP 2GEO. 2011. Geotechnical and foundation design considerations. $120 \mathrm{p}$.

Bolton, M.D., Gui, M.W., Garnier, J. Corté, J.F., Bagge, G., Laue, J. \& Renzi, R. 1999. Centrifuge cone penetration tests in sand. Géotechnique 49(4): 543-552.

DNV. 1977. Rules for the design construction and inspection of off-shore structure, Appendix F, foundations. 5p.

Eurocode 7. 2005. Geotechnical design - Part 1: general rules (NF EN 1997). 145p.
Guefrech, A., Rault, G, Chenaf, N., Thorel, L., Garnier, J. \& Puech, A. 2012. Stability of cast in place piles in sand under axial cyclic loading. 7th Int. Conf. Off-shore Site Investigation and Geotechnics: Integrated TechnologiesPresent and Future, London: 329-334.

Jardine, R., Chow, F., Overy, R. \& Standing, J. 2005. ICP design methods for driven piles in sands and clays. Thomas Telford, London, 105p.

Khemakhem, M., Chenaf, N., Garnier, J., Favraud, C. \& Gaudicheau, P. 2012. Development of degradation laws for describing the cyclic lateral response of piles in clay. 7th Int. Conf. Off-shore Site Investigation and Geotechnics: Integrated Technologies-Present and Future, London: 271-278.

Lings, M.L. \& Dietz, M.S. 2005. The peak strength of sand-steel interfaces and the role of dilation. Soils and Foundations 45: 1-14.

Nivoche, M. 2014. Etude du comportment de fondations d'éoliennes offshore en centrifugeuse sous chargement cyclique axial. Master thesis, IFSTTAR, 90p [in French].

Poulos, H.G. 1988. Cyclic stability diagram for axially loaded piles. Journal of geotechnical engineering 114(8): 877-895.

Rosquoët, F., Thorel, L. \& Garnier. J. 2013. Pile in sand under lateral loading: Development of degradation laws for describing cyclic load effects. Design for cyclic loading: Piles and other foundations, Proceeding of TC 209 Workshop - 18th ICSMGE, Paris: 89-93.

Schneider, J.A., Xu, X., \& Lehane, B.M. 2008. Database assessment of CPT-based design methods for axial capacity of driven piles in siliceous sands. Journal of geotechnical and geoenvironmental engineering 134(9): 1227-1244. 